\title{
レーザポインタを用いた操作系の構築に関する研究
}

\section{Operation interface using command transmission with laser pointer}

\author{
○岩崎 瞬 (芝浦工大) \\ 正 水川 真（芝浦工大） \\ 正 安藤 吉伸 (芝浦工大) \\ Shun IWASAKI, Shibaura Inst. Tech. Toyosu3-7-5, Kouto-ku Tokyo \\ Makoto MIZUKAWA, Shibaura Inst. Tech. \\ Yoshinobu ANDO, Shibaura Inst. Tech.
}

\begin{abstract}
We have been developing the PAS (Physical Agent System) that is the RT system using the remotely controlled semiautonomous robot that can be used as the agent of the operator. The purpose of this research is to provide the "easy" and "intuitive" operation interface for everyone. As the operation device, the laser pointer adopted. The robot searches luminescent point applying image processing. In this system, we proposed to transmit operation commands to the agent robot by superposing digital signal on the blinking pattern of luminescent point of the laser pointer. In this report, it constructs the operation system which uses this laser pointer, being to do it reports the verification of effectiveness.
\end{abstract}

Key Word : Physical Agent System, Laser Pointer, Operation device, Image Processing

\section{1. 緒言}

近年ロボット技術の発展はめざましいものがあり, 近い将来 ロボットが生活環境下に遒入されると予想される.また，高齢 化社会を迎えるに当たって，ロボットは非常に有効である.こう した中でロボットが広く一般に普及していくためには, ロボット の操作が容易であることが重要である. しかし, 現状の操作シ ステムは非常に複雑であり操作を覚えるのに多くの時閒を必 要とし, 高齢者の人にとっては扱いにくいものであると考えられ る.

また, 従来ロボットを遠隔操作する場合は無線等を用いた 機器を使用する事で動作指示を与えている. しかし, 病院等 の無線機器の使用が不可能な環境も世の中には多く存在す る.

そこで本研究では, レーザポイン夕(以下 LP)を用いた容易 な操作システムを構築したので報告する.

\section{Physical Agent System (PAS) (1) (2)}

現在, 遠隔地間コミュニケーションは大きな発展を遂げてい る.しかし, 現在までの遠隔地間コミュニケーションは, 音声や 映像などを用いて行っているため, 遠隔地に「物理的」に作用 することができない。

そこで, 我々の研究室では, 遠隔操作可能な半自律移動口 ボットを, 遠隔地において物理的な作用を及ぼす事が可能な エージェントとして機能させる為のシステムを提案している.こ のシステムを Physical Agent System (PAS) と呼び研究開発 を行っている.

PAS におけるエージェントに, 環境センサ(CCD カメラ, 近接 センサ等)や効果器(アーム, レーザポインタ)を装備することに
より遠隔地からの環境映像を監視しつつ空間を指示すること が可能である. 加えて, センサ, 効果器姿勢の自律安定制御 系を組み込むことにより遠隔地からの観測, 指示を容易にして いることも大きな特徵である. また, 入力系は効果器や作業内 容に応じ複数の入力デバイスを選択し使用できる.これらによ り, 高機能なヒューマンロボットインタラクション研究のプラットフ オーム開発を構築する.

PAS の用途は多種多様であるため, 汎用性を高めるために, $\mathrm{ORiN}^{(3)} \mathrm{RT}$ ミドルウェア ${ }^{(4)}$ 等のミドルウェアを適応している.

また, 開発中のロボット PAR04R では, 各種の機能をモジュ 一ルとして開発し, CAN(Controller Area Network)を用いた分 散制御を行うことで, 用途に忘じてモジュールを容易に付け替 えることが可能である.

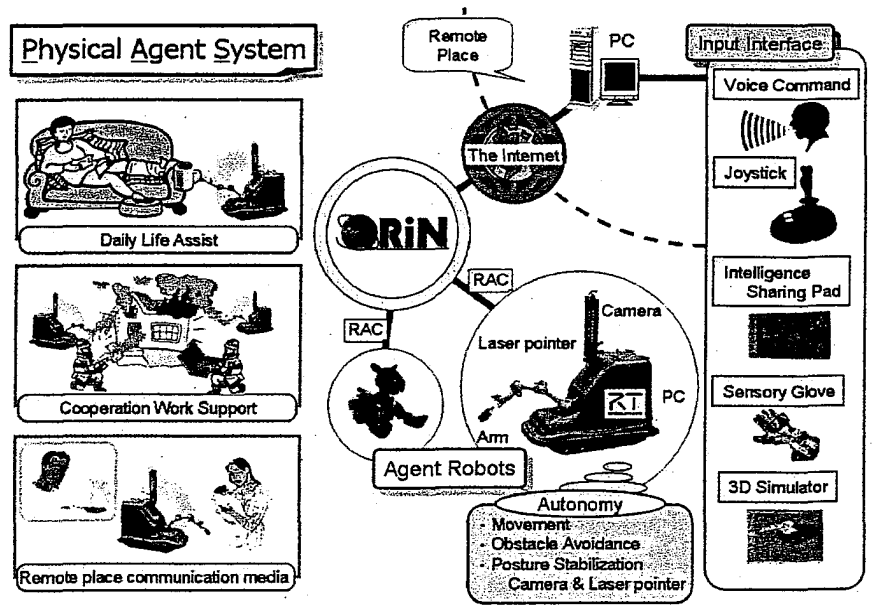

Fig. 1 Outline of PAS 
PAS は従来までの遠隔地間のコミュニケーションと異なり，実 際に物理的にアクションを起こすことが可能なため，様々なサ 一ビスをユーザに提供することが可能となる. 例えば, 机の上 の「あの」ノートや電子レンジの「その」ボタンなど従来の電話等 では伝えることが難しかった抽象的な物体の指示なども容易 に行うことが可能となる.さらに, 従来の遠隔地間コミュニケー ションでは実現不可能であった日常生活支援や危険なために 人が作業不可能な災害地などでの作業などにも利用していく ことが可能である. PAS の構成と適用場面を Fig. 1 に示す.

本研究は, PASの適応場面の一つである, 日常の生活支援 に着目し, エージェントを操作する際の操作デバイスの構築を 行う.

\section{3.レーザポインタを用いた操作系の構築}

\section{1. 既存の操作デバイスの問題点}

現在ロボットを操作する際に用いられている主な入力インタ フェースは, マウスやキーボード, ジョイステイック等が挙げられ る. しかし, これらのデバイスは初心者にとって直感的に操作 方法がわかるといらものではなく, 操作にある程度訓練を必要 とするという問題点がある.

\section{2. 操作デバイスとしてのレーザポインタ}

LP は, ボタンを押すという容易な操作で実空間上の任意の 地点, つまり，操作者の意図する曖昧な，「あれ」や「それ」とい った噯昧な表現を指し示す事が可能である.このような特徵を 持った LP を操作デバイスとして用いることで, エージェントを容 易かつ直感的に操作可能となるのではないかと考えられる.

LP の輝点は高輝度であり, 画像処理を行うことで比較的容 易に抽出することが可能であり, LP の輝点抽出を取り扱った 研究も過去に行われ，エージェントを LP で指示した地点へと 誘導することに成功している(5). しかし, エージェントの誘導に 関しては LP のみで行えるものの, そこで何をしてほしいのかと いった動作内容の指示には他のデバイスに頼る必要性があ る.

そこで, 本研究では, LP の輝点に信号成分を含ませること で，LP のみを用いてロボットへの動作指示を送る手法の検討 を行った. 本研究における LP を用いた操作システムの概要を Fig. 2 に示す. 本報告では, エージェントと操作者が同一空間 上に存在する場合を考える.

LP のみを用いてエージェントロボットに動作指示を与える方 法として，LPの輝点の点滅を利用する. 操作者がボタンを押し ている間，LP はボタンによって規定されているパターンで ON/OFF を出力する.この点滅パターンを信号として利用し, 動作情報を含ませることでエージェントに命令を伝えることが 可能である.

このような方法を用いることで, カメラを搭載したロボットであ れば,レーザポインタのみを用いて様々な指令を与えることが 可能となり, 操作者にとって「容易」かつ「直感的」な操作シス テムが実現する.

\section{3. システム構成}

\subsection{1. 送信側}

レーザポインタの輝点の点滅を制御し，ボタンを押している 間 Fig. 3 のような信号を送信する信号送信用モジュールを作 成した. 信号は, SOF(Start Of Flame), Data Field, CRC Field, EOF(End Of Flame)で構成する. この Data Field 中に，ロボット を識別するための Robot ID と動作内容である Control ID を含 ませ, 特定のロボットに特定の動作を行わせる. SOF, EOF は
それぞれ信号の開始と終了を示し, CRC Field は信号のエラ 一チェック用に用いる.

\subsection{2. 受信側}

受信側ハードウェア構成をFig. 4 に示す. 本システムでは画 像を取得するのに CCD カメラを、輝点抽出には日立情報制御 ソリューションズ社製画像処理ボード”IP7000BD”を使用する.

カメラの画角内に·LP の輝点が映し出されると, 画像処理ボ ードにて画像処理を用いて輝点の抽出を行う. 輝点の座標を 基にカメラの Pitch 軸, Yaw 軸を制御し輝点を追従する. 次に, 任意の点で一定時間輝点が留まっていると判定した後に信号 情報を認識する。得られ信号情報を元にCAN-Message を生 成し, CAN-BUS へ送る. 各サブシステムは, 送られてきた CAN-Message を元に目的の動作を行う.

以上の一連の動作によって, エージェントは操作者の意図 した動作を達成する事が可能である.

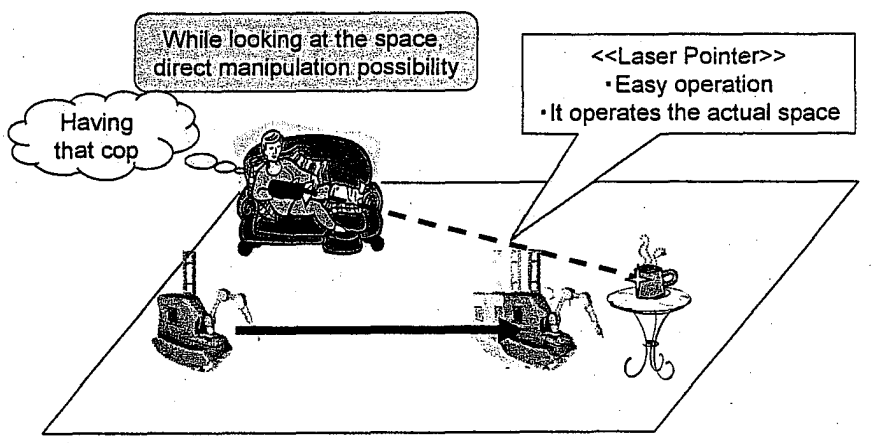

Fig. 2 Outline of operation system using laser pointer

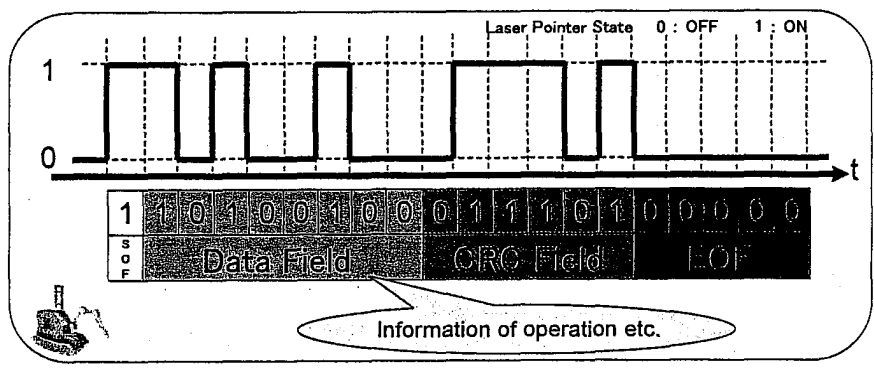

Fig. 3 Data Frame of Signal

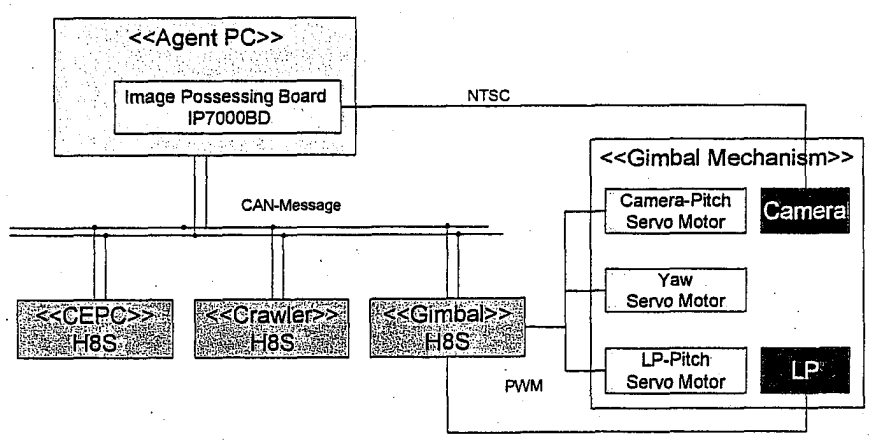

Fig. 4 System configuration figure 


\section{4. 輝点抽出実験}

\section{1. 実験内容}

LP の輝点は高輝度であり, 画像処理によって比較的容易 に抽出する事が可能であると考えられる.しかし, 実際に連続 して抽出するとなると,ノイズの影響を受け安定して抽出する 事は難しい.

そこで, 輝点を安定して抽出するために, 光学フィルタをカメ ラに設置し，輝点以外のノイズが極力少なくなるような方法の 検討を行う. LP の輝点の波長は 650nm である.このため, 光 学フィルタとしてバンドパスフィルタ BPB60, SC(シャープカット) シリーズの光学フィルタ SC64, SC66を用いて輝点の抽出精度 の比較実験を行った。

実験環境を以下に示す。

- 一般的な室内環境

- 安全性を考慮しクラス 2 の LP 使用

- 対象とカメラの距離: $500 \mathrm{~mm} \sim 5500 \mathrm{~mm}$

- 対象物: $70 \mathrm{~mm} \times 55 \mathrm{~mm} \times 80 \mathrm{~mm}$ の直方体(Fig. 5)

\section{2. 実験結果}

実験結果をFig. 6 に示す. Fig. 6 よりSC66を用いた場合は, 全く輝点を抽出する事ができなく, BPB60 を用いた場合は，精 度が安定しない. しかし，SC64 を用いる事で, カメラとLP の距 離が $500 \mathrm{~mm} \sim 5000 \mathrm{~mm}$ の間で精度 $90 \%$ 以上と高い数值が得 ることができる事が判明した.これは, SC64 を用いて画像処理 を行うことで, 輝点の波長以外のノイズを除去することができた ためであると考えられる.

また,この時の輝点抽出処理に要する処理時閒は Fig. 7 に 示すように平均約 $50 \mathrm{~ms}$ である.この処理時間であれば, Fig. 3 に示すような 20bit の信号を認識するまでに要する時間は約 $1000 \mathrm{~ms}$ となる.この位の時間であればテレビ等のリモコン機器 を使用する際の時間と比較しても十分実用的な時間であると 考えられる.

\section{5. 信号認識実験}

\section{1. 実験内容}

LP の点滅パターンの認識を行うに当たって, Bit 同期と Block 同期を考える必要がある. 本システムでは, 受信側とし てカメラ画像による画像処理を用いているため, サンプリング 回数を増やすと処理時間が畦かるためサンプリング数を増や して Bit 同期を取るといら事が難しい.

そこで, 1 bit 当たりのサンプリング回数を 1 回とした状態での 認識率の向上を図る事を考える. この状態で, 認識率が下が る要因として考えられるのは, 輝点の点滅のタイミングと, カメラ の画像取り込みのタイミングが徐々にずれていく点である. した がって, 多少のずれが発生しても正確に信号を認識する方法 として, LP の輝点の ON 時間を変化させる事を考え, 信号認 識率の変化の計測実験を行った.

実感環境を以下に示す。

- 対象とカメラの距離 : $2000 \mathrm{~mm}$

- 光学フィルタ SC64 をカメラに設置

- その他の環境は 4 章の実験と同様

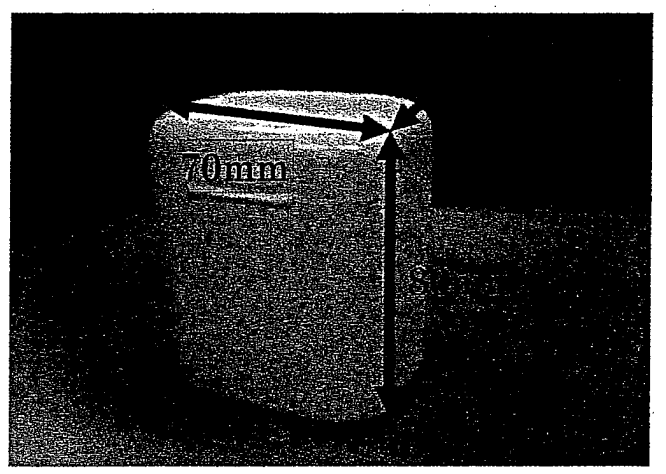

Fig. 5 object of experiment

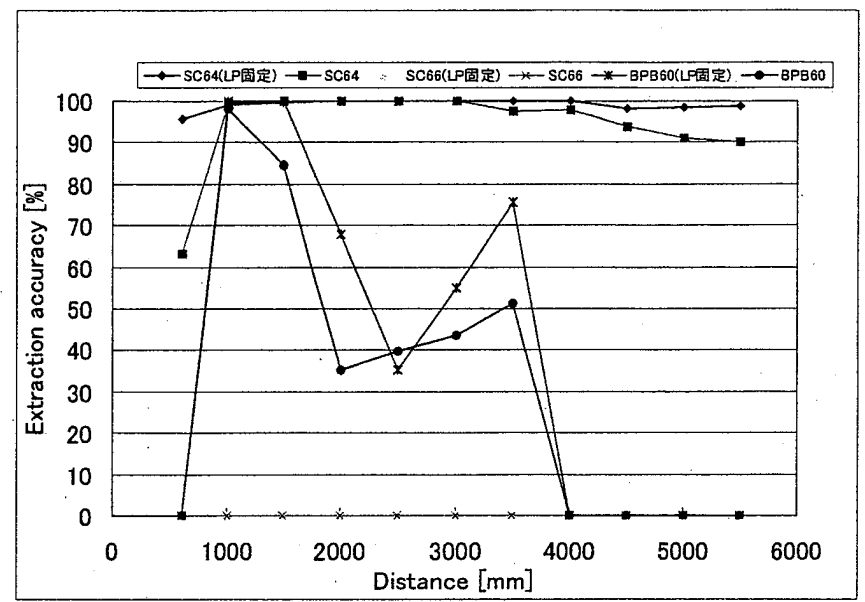

Fig. 6 Experimental result

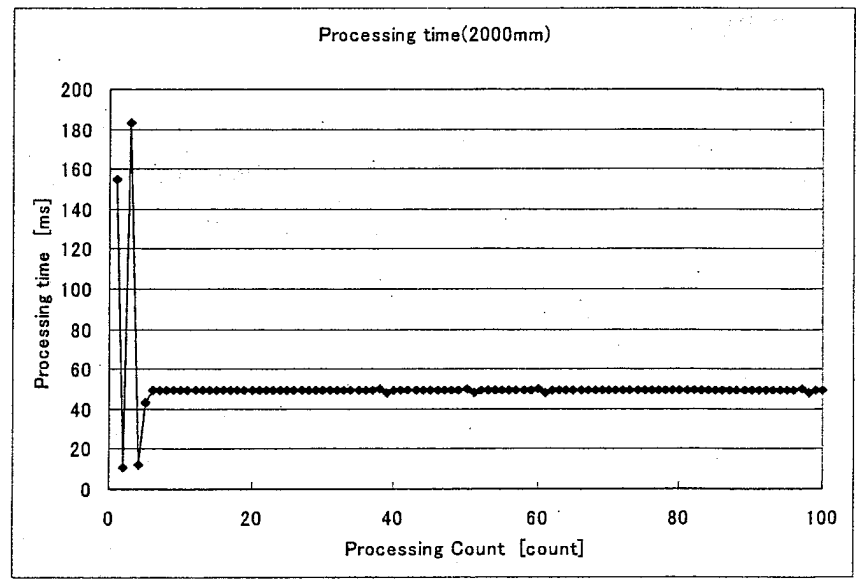

Fig. 7 Processing time

\section{2. 実験結果}

実験結果をFig. 8 に示す. 相関值がどちらの場合も輝点の $\mathrm{ON}$ 時間を $20 \mathrm{~ms} \sim 30 \mathrm{~ms}$ と, 輝点抽出に要する時間の半分程 度に設定する事とで, 信号の認識率が高くなり, $85 \%$ 以上の精 度が得られた。

問題点として, 1 度認識に失敗した状態になると, 連続して 認識に失敗してしまう:これは，Bit 同期を取っていないため， 
タイミングのずれた状態が続くためである.このため, 1 度認識 に失敗した場合は, しばらく操作者は, 目標を指し示した状態 を保持し続けなければならない。

\section{3. タイミング補正}

5.2 の問題を解決するために, 取り込み時のタイミングが完 全にずれ，信号認識に失敗した後，そのずれを修正するように 取り込みのタイミングをずらすために補正時間を設ける処理を 加え,この補正時間による認識率の変化の測定実験を行った. その他の実験環境は 5.1 の実験之同様である.

\section{4. 実験結果（タイミング補正）}

タイミング補正の時間を変化させた時の信号認識率をFig. 9 に示す. Fig. 9より1bit 分ほどの補正時間を加えることで, 精度 が若干であるが向上した. またこの処理を加える事によって 連続して信号認識に失敗することを減少させる事に成功した. したがって, 同じ信号を 2 度送る事で, ほぼ $100 \%$ の精度でエ ージェントに信号を認識させる事が可能となった. しかし, 2 度 送る場合は, $1000 \mathrm{~ms} \times 2$ 回 $=2000 \mathrm{~ms}$ 以上の時間を要する.

\section{6. 結論}

本報告では，容易かつ直感的な操作デバイスとして LPを用 いたシステムの構築を行った. LPの輝点の点滅パターンを利 用する事で, LPで対象を示すと同時に，エージェントに指令を 与える事が可能であることを検証した. 既存の操作デバイスと 比べ, 容易かつ直感的といった点では優れているものの, 信 号情報の認識精度や処理時間といった点では問題もあり改良 していく必要性がある。

また，動作指示方法については，LP のみではなく音声や赤 外線等の他の手段に頼る方法も検討して行く必要性があると 考えられる.

\section{参考文献}

（1）水川真, 松原安彦, 安藤吉伸, 平岩明, 町野保:「物理 エージェント(PAS) を用いた，遠隔地間人間協調系の 基本検討」, 計測自動制御学会システムインテグレーシ ヨン部門学術講演会講演論文集, pp.125-126, 2000

(2) 水川, 安藤:"共創メディアとしての物理エージェントシス テムPAS”, 計測自動制御学会 SI 部門講演会 2002 演 論文集 II, pp279-280

(3)：ORiN 協議会:WWW サイト: http://www.ORiN.jp/

(4) RT ミドルウェア:RT ミドルウェアプロジェクト HP http://www.is.aist.go.jp/rt/

(5) 池内康之, 水川真, 安藤吉伸:「物理エージェントシス テム (PAS)におけるエージェントロボットのガイダンス レーザポインタを用いたエージェントロボットのガイダン スサブシステムの構成-」, 第 10 回ロボティクスシンポジ ア, 講演番号 $=5 \mathrm{~B} 4,2005$

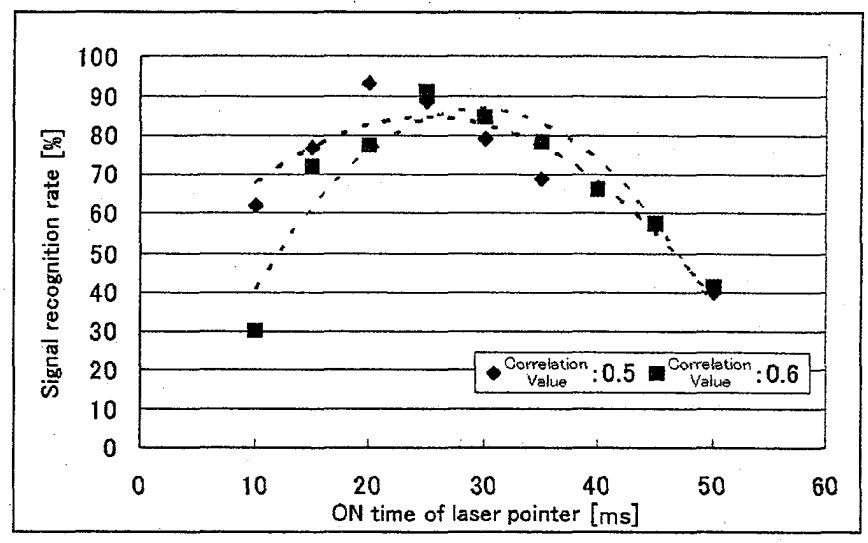

Fig. 8 Signal correct recognition rate

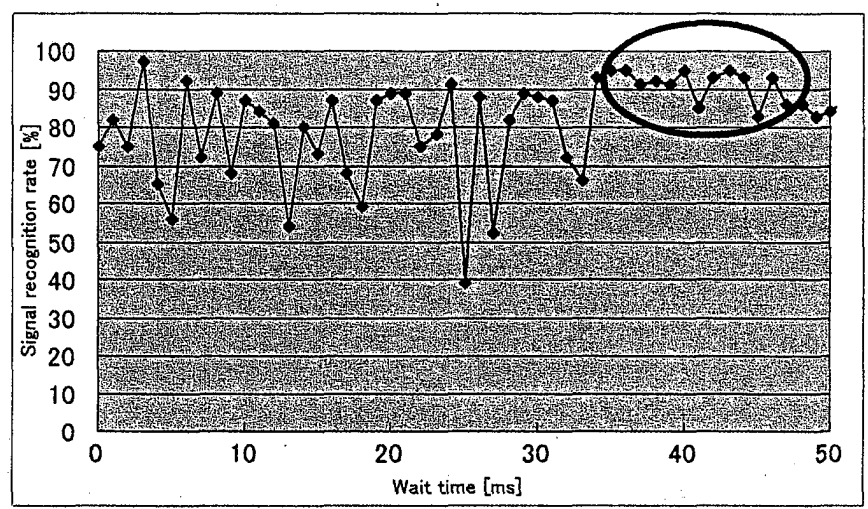

Fig. 9 Change of the signal correct recognition rate with revision time 